\title{
Modelo de Escalas da Visibilidade: Mapeando Percursos de Visibilidade e suas Consequências para Midiativistas do Sul Global
}

\section{The Stepping into Visibility Model: Mapping out Visibility Journeys and their Consequences for Mediactivists from the Global South}

\author{
Andrea Medrado ${ }^{1}$ \\ Isabella Rega ${ }^{2}$
}

\begin{abstract}
Resumo: Neste artigo, desenvolvemos o Modelo de Escalas da Visibilidade para mapear os percursos de visibilidade de midiativistas em países do Sul Global. Desenvolvido com base em observações digitais etnográficas e entrevistas em profundidade, o modelo é aplicado em dois estudos de caso: a) ativistas de uma favela brasileira que utilizam as mídias sociais como proteção contra a violência policial (Maré Vive) e b) um fotógrafo Queniano que produz imagens noturnas de Nairobi para discutir temáticas sociais (Msingi Sasis). O estudo oferece uma discussão teórica acerca do midiativismo e analisa as múltiplas facetas do conceito de "visibilidade". Espera-se oferecer uma contribuição à maneira como ativistas de comunidades marginalizadas podem se fortalecer quando se deparam com uma visibilidade negativa não intencional.

Palavras-chave: Modelo de Escala da Visibilidade; Midiativismo; Sul Global; Favela.
\end{abstract}

Abstract: In this article, we develop the Stepping into Visibility Model, mapping out the visibility journeys of mediactivists from Global South countries. Drawing from digital ethnographic observations and in-depth interviews, we

1 Universidade Federal Fluminense (UFF). Niterói, RJ, Brasil. http://orcid.org/0000-0002-9408-9688 E-mail: andreamedrado@yahoo.com.br

2 Bournemouth University. Bournemouth, Reino Unido.

https://orcid.org/0000-0002-9149-8531E-mail: irega@bournemouth.ac.uk 
apply the model to two case studies: a) activists in a Brazilian favela and their use of social media for protection against police violence (Maré Vive) and b) a Kenyan photographer who produces images of Nairobi at night to discuss social anxiety themes (Msingi Sasis). The study provides a theoretical discussion on mediactivism and analyses the multiple facets entailed in the concept of "visibility. We hope to offer a contribution to activists from marginalised communities by helping them become stronger when stepping into negative unintended visibility. Keywords: Stepping into Visibility Model; Mediactivism; Global South; Favela 


\section{Introdução}

O termo "Sul Global" possui definição ampla e flexível; ele não está literalmente ligado à localização geográfica no Sul, mas, sim, a uma geografia de injustiça e opressão. Citando Boaventura Sousa Santos (2014), os povos do Sul Global são seres humanos largamente diversos, unidos pela ideia de que a compreensão do mundo supera, de longe, a compreensão ocidental do mundo. Trabalhando narrativas pessoais e históricas centradas na fronteira entre os Estados Unidos e o México, Gloria Anzaldúa aborda a geografia do "estar entre lugares" e a importância do escrever desde as margens para a construção de novas epistemologias decoloniais. Aqui, nos interessa em especial uma articulação de política de coalizão entre "escritoras do terceiro mundo" (MORAGA E ANZALDÚA, 1983), utilizando a designação que era comum na época e que não é mais utilizada. Tal coalização é importante porque carrega um forte posicionamento contra a exclusão da alteridade dos lugares privilegiados da construção da modernidade. Assim, é para essa outra e esse outro excluída(o) e marginalizada(o) que dedicamos nossa atenção neste artigo. Nesse sentido, Leonardo Custódio (2016) nos oferece um pano de fundo interessante ao analisar ações políticas periféricas realizadas através da comunicação em diversas partes do mundo. Escrever sobre Sul Global é debruçar-se sobre o conceito de periferia, definido de forma ampla. Para Custódio, a periferia deve ser compreendida:

não só como espaços urbanos heterogêneos que historicamente sofrem com a precariedade de serviços públicos, com a condição predominante do subemprego e com a violência, sobretudo, em sociedades desiguais como a brasileira, mas também como metáfora para a situação de exclusão e/ou discriminação de grupos marginalizados dos espaços legitimados de fala (exemplo: canais de mídia) e esferas de poder, incluído em países comumente tratados como desenvolvidos (2016, p. 139).

Oferecendo um panorama global, Custódio discorre sobre a utilização da comunicação comunitária como instrumento de: a) luta contra 
os impactos da desigualdade social e distância entre trabalhadores e populações pobres e as esferas de poder na América Latina (2016, p. 144); b) valorização de conteúdo local e alternativo às corporações de comunicação na América do Norte (2016, p. 146); c) ampliação de representações políticas, culturais e étnicas na Europa (2016, 147); d) promoção de desenvolvimento com transmissões nos idiomas locais na África (2016, p. 150); e) atuação em vilas rurais e favelas urbanas para promoção de diálogo e informação na Ásia (2016, p. 152); f) valorização da cultura, diversidade e legado dos povos aborígenes na Oceania (2016, p. 153). Tais perspectivas são úteis porque ilustram a variedade e complexidade dos usos da comunicação para a busca de um mundo menos desigual em diversas partes do mundo.

Neste artigo, destacamos práticas comunicacionais midiativistas de dois países situados no Sul Global, respectivamente, nos continentes Latino Americano e Africano: Brasil e Quênia. Nas próximas seções do texto, traremos discussões teóricas sobre visibilidade e midiativismo, colocando o segundo conceito em contraste com outras práticas comunicacionais oriundas das "margens" como a comunicação comunitária. Uma de nossas contribuições é a criação de uma conexão Sul-Sul, reconhecendo que tais conexões trazem desafios significativos, dado o legado colonial de relações fragmentadas entre os povos do Sul Global. Vários autores têm apontado a necessidade urgente de reescrever, reensinar e reaprender as histórias de indígenas e africanos para brasileiros que são descendentes diretos desses povos. Durante séculos, essas histórias foram "disfarçadas, camufladas, desfiguradas ou mutiladas", seja pela força das circunstâncias, da ignorância ou do interesse "(KI-ZERBO, 2010). Essas práticas resultaram das atividades da Rede eVoices Redressing Marginality, financiada pelo Arts and Humanities Research Council (AHRC) do Reino Unido. O objetivo da rede era reunir acadêmicos, profissionais e membros da sociedade civil para trocar conhecimentos sobre como o midiativismo pode combater a marginalização em diferentes contextos do Sul Global. 
Brasil e Quênia foram escolhidos porque, ao analisarmos suas práticas midiativistas, percebemos que o alcance de visibilidade nas mídias sociais, algo almejado por ativistas, gerava momentos críticos nos dois contextos. Isso incluía ataques, discursos de ódio e destruições de reputação, que podiam se transformar até mesmo em ataques físicos. Nos dois países, esses momentos precisavam ser superados para que os midiativistas pudessem continuar utilizando suas páginas e perfis em redes sociais para causas socialmente progressistas. Assim, com o intuito de fornecer aos ativistas uma ferramenta de proteção mútua contra as consequências negativas da visibilidade, desenvolvemos um modelo intitulado "Modelo de Escala da Visibilidade".

Aplicamos o modelo a dois estudos de caso: 1) uma iniciativa midiativista (Maré Vive), criada por moradores de uma favela carioca (a Maré), que utiliza as redes sociais para realizar denúncias contra violações de direitos e violência policial; e, 2) um fotógrafo queniano (Msingi Sasis), que produz imagens de Nairóbi à noite para suscitar uma reflexão sobre questões de desigualdade social. Ao apresentar o modelo, derivado da troca de conhecimentos entre brasileiros e quenianos, o objetivo é oferecer aos midiativistas reflexões sobre a necessidade de planejarem suas jornadas de visibilidade. Isso pode ser relevante quando os midiativistas deparam-se com visibilidades midiáticas negativas e não intencionais. Ao compartilhar essas experiências entre Brasil e Quênia, o artigo traz uma contribuição do e para o diálogo Sul-Sul, abrindo novos caminhos para uma pesquisa ativista e um midiativismo informado por pesquisa.

\section{As Múltiplas Facetas da Visibilidade}

Em sua luta contra as injustiças, os movimentos sociais precisam que essas mesmas injustiças sejam visibilizadas. Em contrapartida, a invisibilidade cria exclusão e marginalização (BRIGHENTI, 2010; ULDAM, 2017). As novas tecnologias, em particular as mídias sociais, emergem nesse cenário como ferramentas importantes para promover a visibilidade com fins de empoderamento. Entre algumas das vantagens estão a facilidade de acesso e a capacidade de não depender dos meios de 
comunicação de massa, expondo arbitrariedades dos governos ou possibilitando que grupos marginalizados narrem suas histórias em seus próprios termos.

No entanto, a visibilidade é uma faca de dois gumes porque pode também atuar como um meio de controle. A visibilidade que as tecnologias da Internet conferem aos atores da sociedade civil, alternativa, pode facilmente resultar em vigilância. Empresas privadas e governos podem usar tais tecnologias para monitorar, censurar e conter vozes dissidentes. Para vários autores (DE BACKER, 2018; ULDAM, 2017), a metáfora do modelo de prisão panóptica de Michel Foucault (1977) nos dá o ponto de partida para a discussão sobre vigilância e controle. Andrea Brighenti chama atenção para a natureza assimétrica da visibilidade. Ele afirma que num contexto natural ideal, "a regra é que se eu posso lhe ver, você pode me ver”, mas as coisas não são assim tão simples. A relação de visibilidade é com frequência assimétrica, e o conceito de intervisibilidade, de reciprocidade de visão, é sempre imperfeito e limitado (2007, p. 326). A eficiência do panóptico depende da invisibilidade do vigilante. Ao mesmo tempo, o papel da invisibilidade não é simplesmente acentuar o poder das autoridades que vigiam, mas tornar o panóptico eficiente através da incerteza. Recorrendo à tecnologia da invisibilidade com o panóptico, o espetáculo da vigilância (a torre) pode ser realizado. Mais ainda, de nada vale a vigilância, por si, para estimular a disciplina. É necessário que haja também a ameaça (e presumivelmente, em determinado ponto, a concretização) da punição. Isso significa que a vigilância tem que ser respaldada pelo poder. Segundo Brighenti, estamos diante de "regimes de visibilidade", que são altamente dependentes de contextos e disposições sociais, técnicas e políticas complexas, o que torna a visibilidade um fenômeno profundamente ambíguo (2010, p. 3).

Para ativistas à margem da sociedade, a visibilidade nas mídias sociais é alcançada majoritariamente em períodos de protestos em larga escala. Como Anthony McCosker pontua, a literatura tem extensivamente examinado o papel das mídias sociais na proliferação das vozes das pessoas marginalizadas, gerando possibilidades para a participação 
cívica em diversos contextos, tais como no Egito, Hong Kong e Espanha (2015, p. 1). Aqui, escolhemos por enfatizar os passos que os midiativistas percorrem no que chamamos de seus percursos de visibilidade. Em vez de analisar visibilidade e mídias sociais em um dado evento em larga-escala, adotamos as perspectivas de midiativistas no Brasil e no Quênia e tentamos seguir seus percursos de visibilidade, refletindo sobre as implicações que o alcance dessa visibilidade (ou, ao contrário, a invisibilidade) pode ter para eles. Mesmo quando ativistas estão conscientes dos problemas causados pelas dinâmicas de vigilância, muitos se veem forçados a correr riscos em troca do alcance e da capacidade de mobilização proporcionada pela visibilidade das mídias sociais. Por exemplo, Lina Dencik et al. constataram que "a dependência das mídias sociais dominantes para executar as agendas ativistas minou os esforços para driblar ou resistir às práticas de vigilância de maneira intensa" (2016, p. 6).

Um considerável número de estudos foca em midiativismo(s) sob uma perspectiva do Norte Global, abordando experiências de países como a Dinamarca (ASKANIUS; ULDAM, 2011), a Alemanha e o Reino Unido (DENCIK et al., 2016), entre tantos outros. Já este estudo oferece uma contribuição à crescente literatura sobre ativismo social no Sul Global (MILAN; TRERÉ, 2019). De fato, a discussão dos potenciais perigos que envolvem a conquista da visibilidade em mídias sociais nos levou a considerar os contextos sociais e políticos específicos do Brasil e do Quênia, ambos localizados no Sul Global.

A despeito de diferenças significativas em termos de políticas públicas de policiamento e segurança no Brasil e no Quênia, o caráter opressivo dessas políticas tem consequências semelhantes na vida cotidiana das pessoas. Tendo investigado ambos os contextos, Chloé Villalobos demonstra que elas "têm raízes no senso de inevitabilidade, praticando um policiamento severo das áreas pobres, informais e habitadas pelas classes operárias como a única solução para as suas respectivas questões de segurança” (2019, p. 41). Ademais, representações mídiaticas caracterizadas por oposições binárias de - "cidade formal" versus "cidade informal", 
o "bom cidadão" versus o "criminoso", e o "Estado" versus o "inimigo" - marginalizam a pobreza e normalizam assassinatos cotidianos (Ibid).

Essas questões trazem desafios adicionais a maneira como os midiativistas do Sul Global lidam com a visibilidade nas mídias sociais. Christina Neumayer e Jakob Svensson (2016, p. 138) oferecem os contornos dos tipos de ativismo ao longo de dois eixos. O primeiro gira em torno de como os participantes se identificam em relação a "outros" atores e instituições sociais, tais como: organizações de mídia, autoridades governamentais e polícia, e se este "outro" é concebido como “inimigo" (antagonismo) ou como "adversário” (agonismo). O segundo eixo diz respeito ao estado de prontidão dos ativistas para agir com desobediência civil, de um modo geral, e em ação violenta ou com danos à propriedade, em particular (NEUMAYER; SVENSSON, 2016, p. 123). Em nossos casos, sugerimos que o midiativismo do Sul Global (em especial, o midiativismo de favela) não é tão guiado pelo modo como essas comunidades veem "outros" atores sociais. Antes de direcionar seu olhar para esses "outros" atores, as favelas já sofrem automaticamente um processo de "outrificação". Elas são tratadas como outros porque as forças societárias as veem como inimigas da cidade que precisam ser excluídas e até mesmo eliminadas. Essa inversão de ordem pode parecer sutil, mas é importante. Ela implica em uma dinâmica na qual o ativismo da favela é moldado precisamente como uma resposta ao tratamento que é dado a essas comunidades, considerando-as como inimigas, negando-lhes a cidadania. Certamente, temos consciência de que midiativistas em outros países são considerados inimigos, assim como acontece no Brasil e no Quênia. Entretanto, sob uma perspectiva do Sul Global, o fato de uma pessoa ter nascido numa comunidade de favela ou shantytown é suficiente para que seja posta numa situação à margem da sociedade, sem ter, necessariamente, se engajado em ações contra-hegemônicas.

\section{Contextualizando e Definindo Midiativismos Plurais}

Múltiplas formas de contestação midiáticas têm sido nomeadas de diversas formas como mídia alternativa, comunicação popular e comunitária 
e, mais recentemente, midiativismo. Não é o foco deste trabalho debruçar-se sobre uma discussão aprofundada acerca das distinções entre os termos. No entanto, é importante destacar que os diferentes termos surgiram em contextos específicos e "foram empregados para descrever práticas historicamente localizadas" (MAZETTI, 2018, p. 79). Para citar alguns exemplos, os anos de chumbo da ditadura militar no Brasil impulsionaram a existência "de uma comunicação alternativa marcada pela resistência e a denúncia”. Já o processo brasileiro de reabertura política fez desabrochar "uma série de iniciativas de comunicação popular, apoiadas em movimentos sociais que se originavam de setores da Igreja Católica, do sindicalismo e de outras associações de base" (MAZETTI, 2018, p. 82). Aqui, Festa (1986, em MAZETTI, 2018, Ibid) sugere uma diferenciação entre comunicação alternativa e comunicação popular por um viés de classe. A primeira seria oriunda do nível médio da sociedade civil, enquanto que a segunda partiria das bases sociais. No entanto, mesmo que a comunicação alternativa tenha cedido espaço para a comunicação popular com a redemocratização do país no final da década de 1980, os dois termos continuaram a ser amplamente utilizados por acadêmicos e comunicadores (MAZETTI, 2018, p. 85).

O midiativismo vem associado ao crescimento no número de usuários da Internet no fim da década de 1990, quando "novas questões e esperanças democráticas começam a ser articuladas no interior das correntes críticas contra-hegemônicas". Isso ocorreu como consequência de algumas características das tecnologias digitais que favoreciam as mobilizações comunicacionais. Entre elas, podemos citar:

1) a redução dos problemas de liderança; 2) a redução dos custos de difusão; 3) a inserção de modelos de comunicação 'muitos-para-muitos' (em contraste ao modelo 'um-para-muitos' das mídias tradicionais); e 4) a facilitação da produção colaborativa e o alargamento dos espaços de participação (MAZETTI, 2018, p. 86).

Nos dias atuais, algumas dessas premissas da internet como catalizadora de transformações soam romantizadas e até ingênuas diante da concentração de propriedade das gigantes tecnológicas como Google, 
Apple, Facebook, Amazon e Microsoft (GAFAM). Ainda assim, com seu caráter e objetivos contra-hegemônicos, o midiativismo segue operando nas brechas de espaços hegemônicos corporativos (ULDAM, 2017). Com isso, midiativistas encontram obstáculos ao tentar desafiar lógicas algorítimicas, que não favorecem seus propósitos sociais (em vez de lucrativos), e têm seus rastros digitais coletados e utilizados para fins de perseguição e vigilância, como vamos demonstrar mais adiante.

Mesmo operando nesses territórios contraditórios e complexos, no contexto brasileiro, como destaca Cicilia Peruzzo, o midiativismo tem raízes nos movimentos populares e nas organizações sociais progressistas. A autora acrescenta que a atuação desses movimentos midiativistas costuma ser ampla, "não se configurando apenas em comunidades virtuais e/ou em perfis (redes) digitais em "sites de redes sociais", como Facebook, Twitter etc.”. Para citá-la na íntegra:

Sua presença também é constituída de meios (canais), ou seja, sites, blogs, plataformas colaborativas tipo Wiki, canais do YouTube e/ou no Vimeo, de redes formadas dentro de aplicativos (WhatsApp, Instagram etc.), da criação e do uso softwares livres e de aplicativos alternativos, e de vários outros tipos de instrumentos de comunicação, transmissão de dados, articulação, mobilização, de denúncia e pedido de apoio, tais como: petições e abaixo-assinados, plataformas de consultas, plataformas streaming, fóruns, votações, campanhas, ferramentas de busca (hashtags), games (jogos) e símbolos representativos, emocionais ou satíricos (desenhos, memes etc.) que viralizam na Internet (2018, p. 52).

Tendo oferecido uma contextualização histórica, faz-se necessário responder à pergunta: $\mathrm{O}$ que, afinal, seria midiativismo? Antônio Braighi e Marco Câmara afirmam que midiativismo representa mais que uma fusão entre as palavras "mídia" e "ativismo". Midiativismo configura uma simbiose na medida em que "mediação sem ativismo é registro midiático simples" e "ação direta sem artefato medium é ativismo puro". Portanto, é na intercessão das duas frentes, e na sua manifestação da forma mais simultânea possível que se dá o midiativismo (2018, p. 33). Com inspiração no trabalho de Tim Jordam (2002), os autores explicam 
como desmembrar o "quase-binômio" mídia-ativismo. Ativismo refere-se ao:

conjunto de investidas com propósito de alteração da realidade social estabelecida. Estas são empreendidas por sujeitos que, juntos, compartilhando sentimentos acerca de uma determinada conjuntura pública, envidam esforços num sentido comum. Tendo a lógica solidária como referência, visam a alteração das formas usuais como suas vidas são vividas (BRAIGHI E CÂMARA, 2018, p. 33).

O elemento midiático resulta da influência recíproca da tecnologia e da manipulação dela pelo sujeito agente do e no ativismo. Ele parte do reconhecimento que ativistas estão engajados em múltiplas mediações sustentadas por dispositivos midiáticos que não verticalizam seu modo de agir, mas ajudam a conformar modos específicos e estratégicos do fazer ativismo (BRAIGHI e CÂMARA, 2018, p. 35). Portanto, o midiativismo configura uma soma entre as perspectivas ativistas e o processo clássico de mediação. No entanto, citando mais uma vez Braighi e Câmara, "ser midiativista não é apenas portar uma mídia”. É preciso estarmos atenta(o)s aos usos e propósitos. Ou seja, mais que um neologismo sintático, o midiativismo forma um quase binômio e gera um híbrido que deve ser equacionado e equilibrado, combinando funções de informação e mediação para alterar a realidade. Em outras palavras, o midiativismo "é o que se faz dele, desde que não se perca de vista o propósito de mudança social, o efetivo envolvimento e que se mantenha a transgressão solidária” como objetivo (BRAIGHI e CÂMARA, p. 2018, p. 39). Na próxima seção, discutiremos as abordagens metodológicas utilizadas, com a incorporação de dois estudos de caso de iniciativas midiativistas do Brasil e do Quênia.

\section{Metodologia}

Segundo Helen Simons, a abordagem de estudo de caso representa "uma investigação em profundidade de um projeto, política, instituição, programa ou sistema específico da vida real, com a finalidade de capturar 
suas complexidades e singularidades" (2009, p. 21). Em particular, os estudos de casos apresentados neste artigo são de âmbito interpretativo, de acordo com a classificação de Sharam Merriam (1998), pois são usados para desenvolver o Modelo de Escalas da Visibilidade indutivamente, mapeando o modo como a visibilidade afeta grupos de midiativistas.

Com página no Facebook, perfil no Instagram e no Twitter, o Maré Vive (https://www.facebook.com/Marevive/; @Marevive) foi criado para fazer a cobertura da entrada das Forças Armadas na Favela Maré, no Rio de Janeiro, em 5 de abril de 2014. Hoje, no momento da redação deste artigo, a página já conta com mais de 160 mil curtidas. Em todas as redes sociais (Facebook, Twitter, Instagram), o "Maré Vive" descreve-se como "um canal de mídia comunitária feito de forma colaborativa. Nossas notícias são desenvolvidas através da colaboração dos moradores, o canal é feito por todos nós aqui da Maré”. Além disso, a seguinte descrição pode ser encontrada na aba "história" na fanpage do Facebook:

Mantemos as notícias constantemente sendo atualizadas, enquanto chegam informes e relatos, assim diminuímos os riscos de cometer erros ou publicar algum dado equivocado. Sua contribuição é fundamental para que possamos levar as notícias de forma rápida e confiável. Nossa política é manter o anonimato das pessoas que colaboram com a página [...] Não temos nenhum posicionamento anti-exército, anti-polícia ou qualquer outro na hora de noticiar um fato. Nosso posicionamento é sempre em favor dos moradores, esse sim é nosso lado e não temos problema nenhum em assumir isso. Tamo junto, Favela! \#marévive (MARÉ VIVE, 2018, online, em MEDRADO et al., 2018, p. 288).

Msingi Sasis é um fotógrafo queniano que abriu uma empresa de produção e empreendimentos culturais chamada Nairobi Noir, trabalhando com diversas formas de expressão, da escrita (poemas e contos) às artes visuais (vídeo e fotografia) e sonoras (música e gravações de campo das ruas de Nairobi). A perspectiva "noir" (a cor negra, em francês) de Msingi Sasis revela-se em fotos preto e branco de Nairobi à noite, permitindo-lhe captar e documentar questões sociais na capital queniana, como corrupção, prostituição, ansiedade social, moradores de rua e 
pobreza. Ao explicar os propósitos do projeto midiativista, Sasis afirma que:

Nairobi Noir origina-se de uma crítica social muito disfarçada, voltando-se a questões que às vezes foram escamoteadas. [...] quando você olha para o lado escuro de uma cidade, você consegue abordar muitos problemas sociais de um jeito que as pessoas não acham ofensivo, excessivo ou óbvio demais. Não fica com aquela cara de protesto tradicional. [...] você consegue abordar todas essas questões de forma indireta (entrevista com Msingi Sasis, 26/08/2018).

Nos dois casos, percebemos de forma evidente um midiativismo feito com propósito de revelar aspectos dolorosos de realidades marginalizadas, visando uma transformação social. No caso de Sasis, temos um midiativismo em diálogo próximo com a arte e com a experimentação criativa (PASQUINELLI, 2002). Já no caso do "Maré Vive", temos uma iniciativa que busca um posicionamento coletivo orientado pela filosofia do "nós por nós", caracterizada pelo princípio que os moradores de favela devem se encarregar de contar suas próprias histórias (MEDRADO et al., 2018).

Como já afirmamos, Brasil e Quênia compartilham algumas importantes semelhanças. Rio de Janeiro e Nairobi são duas cidades globais marcadas por gritantes desigualdades e conflitos sociais. Seus ambientes urbanos revelam políticas de Estado que tendem a discriminar as populações economicamente vulneráveis através da oferta de sistemas de transporte precários, acesso à saúde e educação deficiente e políticas de segurança pública que frequentemente desrespeitam seus direitos. Execuções extrajudiciais são comuns nos assentamentos informais de Nairóbi e nas favelas do Rio, onde a "guerra às drogas", entre outros argumentos, serve para justificar a adoção da lógica de "atirar primeiro e perguntar depois". Em consonância com esse discurso, "aqueles que são considerados 'bandidos' podem e devem morrer”. Inerente a essas políticas é um projeto em que a elite política e econômica tenta fazer uma limpeza na paisagem urbana daquilo que não se encaixa no modelo neoliberal moderno (VILLALOBOS, 2019). 
Com relação à coleta de dados para os dois casos, ela consistiu em:

a. Observações etnográficas digitais de iniciativas midiativistas de favelas no Brasil, especialmente o perfil do "Maré Vive" no Facebook (@marevive), entre os meses de janeiro e dezembro de 2017.

b. Observações etnográficas digitais nos perfis de Facebook e Instagram do Nairobi Noir (@nairobinoir) entre os meses de setembro a janeiro de 2018 (após ida das pesquisadoras a Nairóbi).

c. Nove entrevistas em profundidade com midiativistas quenianos, durante o evento "In/visible Margins", promovido na cidade pela Rede eVoices Redressing Marginality, entre 20 e 25 de agosto de 2018, e oito entrevistas em profundidade com midiativistas de favela brasileiros, conduzidas entre 14 e 16 de maio de 2018.

d. Notas de trabalho de campo produzidas pelos autores, durante eventos produzidos pela Rede eVoices Redressing Marginality, em Niterói-Brasil (maio de 2018) e em Nairóbi-Quênia (agosto de 2018).

Em termos de procedimentos éticos, a aprovação para a condução desta pesquisa foi concedida pelo Comitê de Ética da Universidade Federal Fluminense e Bournemouth University (através da aprovação da proposta pela Plataforma Brasil). Por questões de segurança, os nomes verdadeiros dos midiativistas envolvidos na iniciativa do "Maré Vive" não foram revelados, pois eles lidam constantemente com questões sensíveis, como a violência policial. Msingi Sasis nos deu permissão para usar seu nome verdadeiro, já que sua história foi publicada em vários meios de comunicação no Quênia e em outros países.

Tendo apresentado uma contextualização dos nossos estudos de caso - "Maré Vive", no Brasil, e Nairóbi Noir, no Quênia - esperamos oferecer uma contribuição do Sul Global para estudos que analisem esforços de contra-vigilância de midiativistas para mitigar riscos e se autoprotegerem. Para alguns autores, esses esforços podem ser tratados como sousveillance (MANN, 2004), em um jogo de palavras no qual o prefixo "sur" da palavra surveillance (vigilância), é substituído por "sous", que, 
em francês, significa "de baixo" para descrever "a vigilância que vem de baixo".

No entanto, o problema é que, muitas vezes, esses esforços tendem a focar no solucionismo tecno-legal, com a implicação de que eles "acabam ficando circunscritos num discurso especializado entre experts" (DENCIK et al., 2016, p. 5). Portanto, é relevante que se compreenda até que ponto ativistas comprometidos com questões de justiça social se engajam em agendas de vigilância. Neste artigo, seguimos essa linha de pensamento, analisando como os midiativistas no Brasil e no Quênia experimentam a vigilância e como administram suas visibilidades.

\section{O Modelo de Escalas da Visibilidade aplicado ao "Maré Vive"}

\section{a) Contexto:}

No dia 30 de março de 2014, o governo instalou tropas Federais no Complexo da Maré, um conjunto de dezesseis favelas localizadas na Zona Norte do Rio de Janeiro. Composta por 2.700 oficiais militares, tanques blindados e jipes com metralhadoras, a ocupação estava prevista para durar até 31 de julho de 2014, logo após o término da Copa Mundial de Futebol da FIFA. Foi nesse clima tenso que um grupo de jovens midiativistas decidiu criar um perfil no Facebook chamado "Maré Vive” (www.facebook.com/Marevive/; @Marevive). O objetivo era cobrir e monitorar a ocupação militar, sob a ótica dos moradores da favela.

\section{b) Crescimento de Visibilidade:}

Com base em nossa pesquisa, percebemos que o "crescimento de visibilidade" se dá quando as iniciativas midiativistas estão em estágios emergentes. Eles adotam estratégias para propagar suas mensagens e chamar atenção para suas causas e lutas. No caso do "Maré Vive", isso ocorreu quando os midiativistas decidiram estabelecer uma ferramenta de contra-vigilância (DENCIK et al., 2016) ou de "sousveillance", a vigilância que vem de baixo (MANN, 2004) para proteger os moradores. Assim, começaram a se dedicar à documentação dos abusos das 
autoridades, filmando, fotografando ou recebendo vídeos e fotos feitos pelos seguidores dos perfis. Entretanto, os ativistas optaram por descrever a iniciativa não como uma contra-vigilância da ocupação militar, mas, sim, como uma filosofia de "nós por nós", que se manifesta quando os moradores da favela se tornam narradores de suas próprias histórias.

\section{c) Alcance da Visibilidade:}

Neste estágio, os midiativistas estão obtendo sucesso na divulgação de sua mensagem tanto para membros de seu círculo quanto para uma audiência mais ampla. Em grupos que apresentam atividade online significativa, esse momento pode corresponder ao alcance de altas métricas de engajamento nas redes sociais, por exemplo. No caso do "Maré Vive", logo após a criação do perfil, uma enxurrada de queixas contra abusos das autoridades foi compartilhada nas mídias sociais, acompanhada das hashtags \#OqueaMarétem, \#dedentrodaMaré e \#MaréVive. O perfil então conquistou 50 mil seguidores e likes em três meses. Administrada por três midiativistas que permaneciam constantemente online, atualizando as informações, a página começou a publicar regularmente postagens sobre diversos tópicos, tais como: eventos locais, oportunidades de emprego, mensagens motivacionais e imagens que se referiam à memória coletiva da favela. Como foto de perfil, a página exibia a fotografia de Dona Orosina, uma das primeiras moradoras da favela. A página começou a atrair a atenção de moradores da Favela da Maré, de outras favelas e áreas do Rio de Janeiro pelas atualizações regulares e imediatas das operações conduzidas pela polícia na favela. 
Figura 1 - Postagem publicada às 05:17, em 21 de novembro de 2017

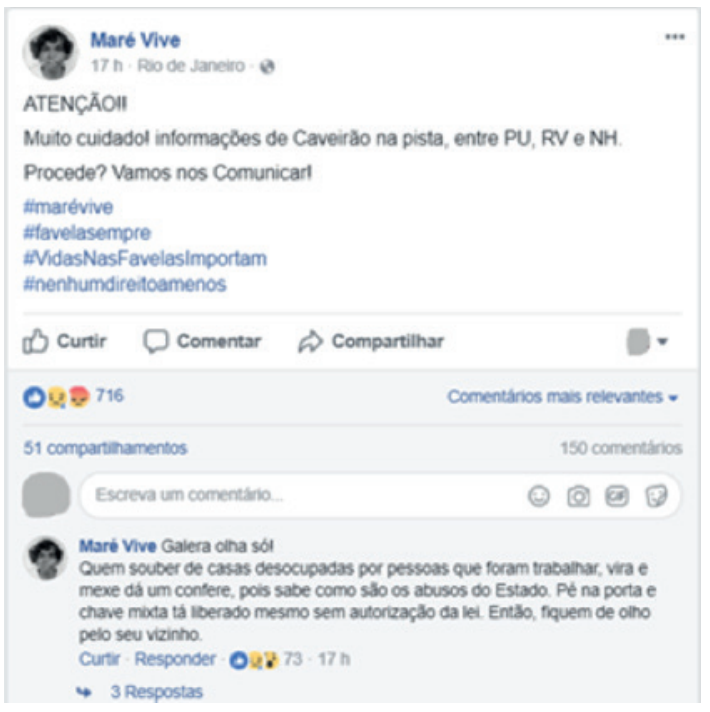

Fonte: Reprodução - Captura de tela.

\section{a) Momento Crítico:}

Aqui, o crescente grau de visibilidade tem a probabilidade de levar a um momento crítico. Com frequência, esse momento é imprevisto. Ele também é influenciado pela marginalização e "outrificação" dos ativistas na sociedade. Desta maneira, grupos de ativistas que atingem picos de visibilidade inevitavelmente se colocam em posição vulnerável, tornando-se vítimas de sérios ataques e de repressão pelas autoridades. Para o "Maré Vive", a página rapidamente se tornou um recurso bastante visível para a sobrevivência cotidiana. No entanto, essa visibilidade teve um alto preço. Em 2015, um ano após a criação do perfil “Maré Vive”, os midiativistas ficaram chocados ao descobrir uma versão falsa da sua página no Facebook. O perfil falso começou a publicar fotos de supostos varejistas de drogas, o que colocou a vida dos administradores do perfil em perigo, pois eles começaram a receber ameaças de morte tanto da polícia quanto dos varejistas. Os ativistas acreditam que tamanha hostilidade pode ter resultado da rápida visibilidade que o "Maré Vive" alcançou. 


\section{b) Gerenciamento do Momento Crítico:}

Com este modelo, sugerimos que a maneira com que os ativistas lidam com o momento crítico é essencial para determinar o tempo de vida e, em última instância, o destino dessas iniciativas, assim como o alcance do quarto estágio de visibilidade. Para gerenciar seu momento crítico, os ativistas do "Maré Vive" decidiram entrar em contato com repórteres da TV Record. Dessa forma, conseguiram desafiar as estruturas de silêncio (LOKOT, 2018, p. 342) da mídia dominante em relação aos moradores da favela e suas vidas nessas comunidades. A estratégia foi bem-sucedida: a TV Record veiculou uma matéria sobre a página falsa no Balanço Geral. A matéria ajudou a esclarecer a confusão, mostrando que o perfil verdadeiro do "Maré Vive" tinha como objetivo publicar notícias locais, na visão da favela, e não denunciar a identidade de criminosos.

\section{c) Superação do Momento Crítico:}

Se as estratégias postas em prática para o gerenciamento do momento crítico forem bem-sucedidas, o grupo midiativista é capaz de superar a crise e trabalhar a favor de seus objetivos a longo prazo. Esses podem incluir, por exemplo, o desejo de crescer e alcançar um círculo mais amplo ou, de maneira oposta, a decisão de ficar mais escondido do olhar público. Para o "Maré Vive", depois que a matéria foi exibida no Balanço Geral, a página falsa desapareceu do Facebook. Um perfil falso adicionou um dos administradores do "Maré Vive" no Facebook, e enviou um pedido de desculpas via mensagem inbox. 
Figura 2 - Página falsa do "Maré Vive", com referências ao super-herói dos quadrinhos Batman, que também representa um símbolo das milícias no Rio de Janeiro.

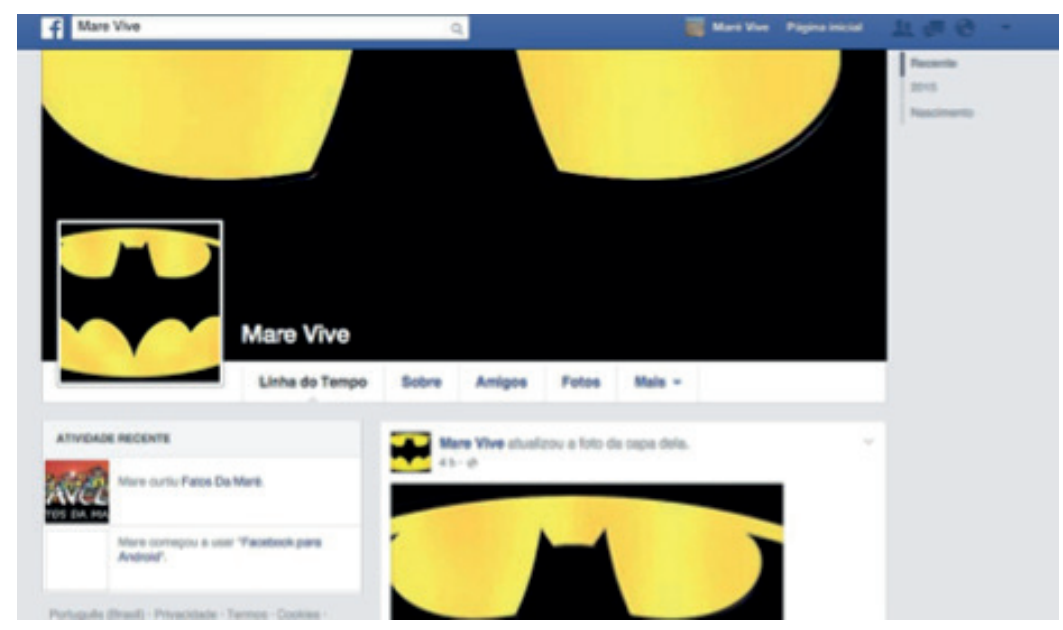

Fonte: Reprodução - Captura de tela.

\section{d) Retração pelo Momento Crítico:}

O momento crítico da visibilidade pode atingir um grupo ou um coletivo duramente, a ponto de eliminar do ecossistema midiativista, ou, o que é ainda mais trágico, resultar em violência e morte. Miller (1999), por exemplo, nota que alguns grupos podem tornar-se vítimas de seu próprio sucesso, sem conseguir lidar com a rápida expansão que vem com a visibilidade. Como consequência de tensões na organização da iniciativa, eles podem se fragmentar ou até mesmo desativar a iniciativa. Isso não ocorreu com o "Maré Vive", mas pode acontecer em outros casos.

\section{e) (Novo) Alcance da Visibilidade:}

O perfil "Maré Vive" tem atualmente 6 anos de atividade, tendo atraído mais de 164 mil seguidores ${ }^{3}$. O tempo trouxe mais maturidade e uma melhor organização interna, e os ativistas decidiram ter um time rotativo publicando as postagens e interações com os moradores. Essa é uma maneira de assegurar que as pessoas por trás da página permaneçam

3 Em novembro de 2020, quando esse artigo foi escrito. 
anônimas, e que novos grupos de jovens midiativistas sejam treinados para assumir responsabilidades, garantindo, assim, que a iniciativa não morra, caso os ativistas mais experientes não possam continuar envolvidos.

Figura 3 - Apresentamos uma representação gráfica do Modelo de Escalas da Visibilidade.

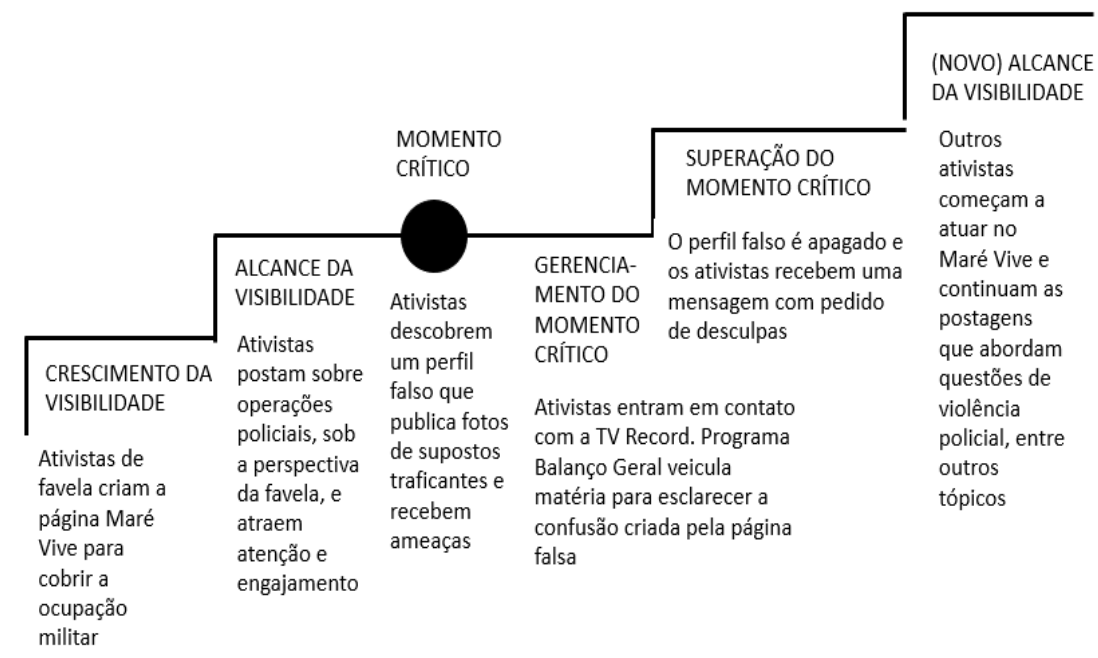

Fonte: Elaborado pelas autoras.

Observamos que os midiativistas das comunidades marginalizadas precisam alcançar a visibilidade como um primeiro passo para qualquer campanha ou ação coletiva bem-sucedida, porque a visibilidade é fundamental para o reconhecimento (BRIGHENTI, 2007). Entretanto, argumentamos que, para os ativistas de favela, que são rotulados como inimigos da sociedade (NEUMAYER; SVENSSON, 2016), alcançar tal visibilidade inevitavelmente irá levar a uma crise. Com o "Maré Vive”, esse ponto crítico aconteceu após a página atrair atenção para a natureza violenta de muitas das operações policiais, o que levou ao ataque virtual à página. Curiosamente, para se defender, os ativistas desenvolveram uma estratégia para alcançar uma visibilidade ainda maior, entrando em contato com uma 
rede comercial de TV. O resultado foi a tensão entre a necessidade de se tornar visível e o risco de ficar vulnerável (LOKOT, 2018).

O estudo do caso seguinte vai discutir como o alcance de visibilidade gerou uma crise para o midiativista queniano Msingi Sasis.

\section{O Modelo de Escalas da Visibilidade aplicado ao Nairobi Noir}

\section{a) Contexto:}

No fim de 2007, o Quênia realizou eleições gerais, com a disputa pelo cargo máximo entre Mwai Kibaki e Raila Odinga, líder do partido de oposição, o Movimento Democrático Laranja. Declarações de que a votação havia sido manipulada deram origem a tensões partidárias, com violentas manifestações por todo o país. Mais de 1.100 pessoas foram mortas e mais de 500 mil pessoas foram forçadas a fugir de suas casas. Nesse período, a mídia desempenhou um papel significativo como combustível para essas divisões étnicas, através da construção e disseminação de narrativas que provocaram a hostilidade interétnica (WACHANGA, 2011).

A consequência dessa experiência deixou marcas na sociedade Queniana. Os artistas, em particular, reagiram através de uma combinação criativa de usos de tecnologias ativistas e táticas estéticas (LOKOT, 2018). As mudanças no cenário tecnológico também facilitaram a promoção e compartilhamento de opiniões em espaços virtuais (em adição ao espaço físico). Cartunistas, animadores, músicos e artistas multimídia criaram uma grande variedade de conteúdo, diferente da mídia tradicional, que foi distribuído online (CALLUS, 2018).

Nesse contexto, Boniface Mwangi, um fotojornalista premiado que havia documentado os eventos de violência nas eleições de 2007, decidiu criar uma organização que reunisse artistas que desejavam usar sua arte para promover mudança política e social. A PAWA254 foi criada em 2009 como uma entidade sem fins lucrativos. É hoje um forte núcleo artístico e cultural do Quênia que abriga, incentiva e catalisa projetos criativos voltados à comunidade, com o objetivo de mudança social. 
Msingi Sasis, o fundador do Nairóbi Noir (www.nairobinoir.org), é parte desse núcleo e sua história é mais um exemplo interessante da face ambígua dos regimes de visibilidade (BRIGHENTI, 2007). A história de Msingi mostra o poder das mídias sociais e da internet para proteger e apoiar ativistas e sua causa, mas também salienta o outro lado da moeda, os riscos conectados à visibilidade e à importância da reputação online.

\section{b) Crescimento da Visibilidade}

Em 2012, o trabalho de fotografar as ruas de Nairóbi após o Pôr do Sol ainda era considerado um hobby até que 2 anos depois, em 2014, ele editou uma dessas fotos e a postou no Facebook, tendo 500 curtidas da noite para o dia. A partir de então, Msingi começou a escolher uma das centenas de fotos que fazia por dia, editando e publicando sempre uma foto por dia durante 2 anos. As fotos alcançaram repercussão com seus seguidores e a popularidade dele começou a crescer.

\section{c) Alcance da Visibilidade}

Após um mês de postagens, o fotógrafo recebeu uma mensagem pelo Facebook da PAWA254 com um convite para exibir seu trabalho em um evento internacional, o "African Metropolis". Para essa ocasião, Msingi decidiu então criar um website e estabelecer a marca Nairobi Noir.

Figura 4 - Captura da página no Facebook da Nairobi Noir.

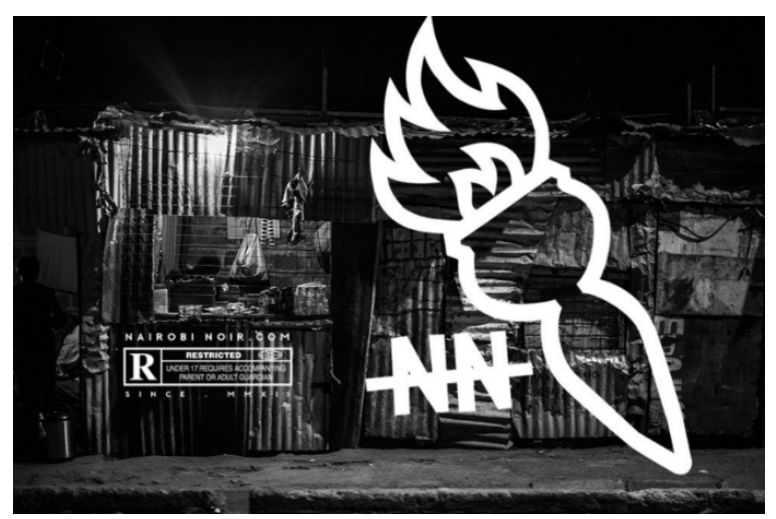

Fonte: Reprodução - Captura de tela. 


\section{d) Momento Crítico}

Em abril de 2015, ele saiu após o Pôr do Sol, como de costume, para fotografar a cidade e o Shopping Center Galleria Mall e algumas pessoas ficaram desconfiadas com sua presença. O Quênia ainda estava sob o impacto de ataques terroristas no Shopping Westgate, em 2013, que causaram a morte de 71 pessoas e deixaram 200 pessoas feridas. Dessa forma, as pessoas no local começaram a estranhar a situação e a espalhar rumores que Msingi estaria planejando atos de terrorismo. A multidão começou a agir de forma violenta e Msingi quase foi linchado até que a polícia foi chamada e prendeu o fotógrafo.

Figura 5 - Captura de tela do Twitter de Boniface Mwangi.

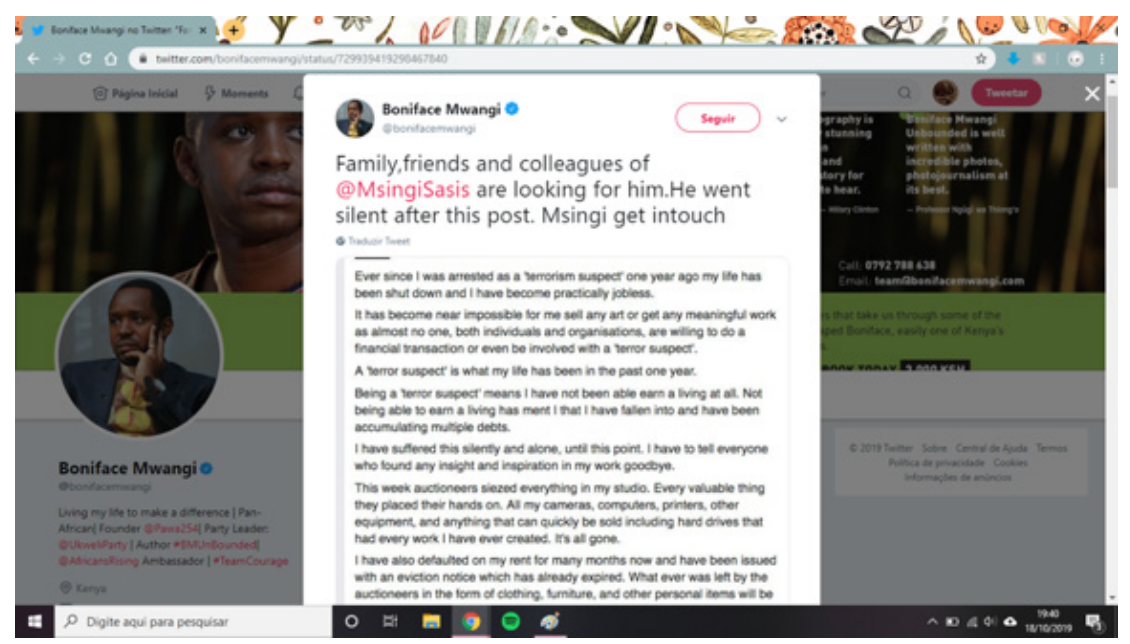

Fonte: Reprodução - Captura de tela.

\section{e) Gerenciamento do Momento Crítico}

Após o massacre no Shopping Westgate e outros ataques terroristas que ocorreram no país, o governo queniano aprovou uma Lei de Alteração das Leis de Segurança (Security Law Amendment Act), em dezembro de 2014. Entre outras medidas, essa lei concedeu à polícia o direito de manter qualquer suspeito de terrorismo sob custódia por 360 dias, sem divulgar o caso ao público. Portanto, quando a família de Msingi foi 
procurá-lo e a polícia não confirmou sua prisão, eles buscaram a ajuda de Boniface Mwangi, o fundador da PAWA254.

\section{f) Superação do Momento Crítico}

A organização PAWA254 iniciou uma campanha online, nas redes sociais, para denunciar a prisão de Msingi e fazer pressão para que o fotógrafo fosse libertado. Eles tiveram sucesso e ele foi solto em 24 horas.

Depois que fui preso, tive um apoio e um incentivo imenso e senti que não podia simplesmente deixar uma prisão me parar. Para todas essas pessoas, meu trabalho teve grande ressonância. Muita gente me dizia o quanto meu trabalho havia aberto seus olhos [...] (Entrevista com Msingi Sasis, 26/08/2018).

Sua prisão representou um incidente de vigilância panóptica. Podemos inferir que as excursões fotográficas de Msingi pelas ruas de Nairobi à noite haviam sido observadas pelas autoridades. Consequentemente, o clima de tensão e desconfiança que ecolodiu na fatídica noite quando foi preso ofereceu (de forma injusta) uma justificativa para sua prisão e punição (FOUCAULT, 1977).

\section{g) (Novo) Alcance da Visibilidade}

Depois da prisão, Msingi voltou a fotografar, tanto para o projeto Nairóbi Noir, quanto em seu estúdio. No entanto, os clientes começaram a se afastar do fotógrafo porque notícias que o identificavam como suspeito de terrorismo começaram a se espalhar online e nas mídias sociais. Esse processo gerou uma espécie de visibilidade negativa involuntária, trazendo consequências não intencionais para ele.

\section{h) Momento Crítico}

$\mathrm{O}$ artista passou a não conseguir levar adiante projetos profissionais e começou a ficar endividado. Passou a dever o aluguel e foi despejado, ficando desempregado e sem teto. Esse foi um momento extremamente difícil na vida de Msingi. No entanto, mais uma vez, a rede de ativistas 
reunida pela PAWA254 ofereceu apoio ao fotógrafo e criou uma campanha online para encontrá-lo e visibilizar seu tratamento injusto.

Figura 6 - Captura de tela, Twitter de Boniface Mwangi.

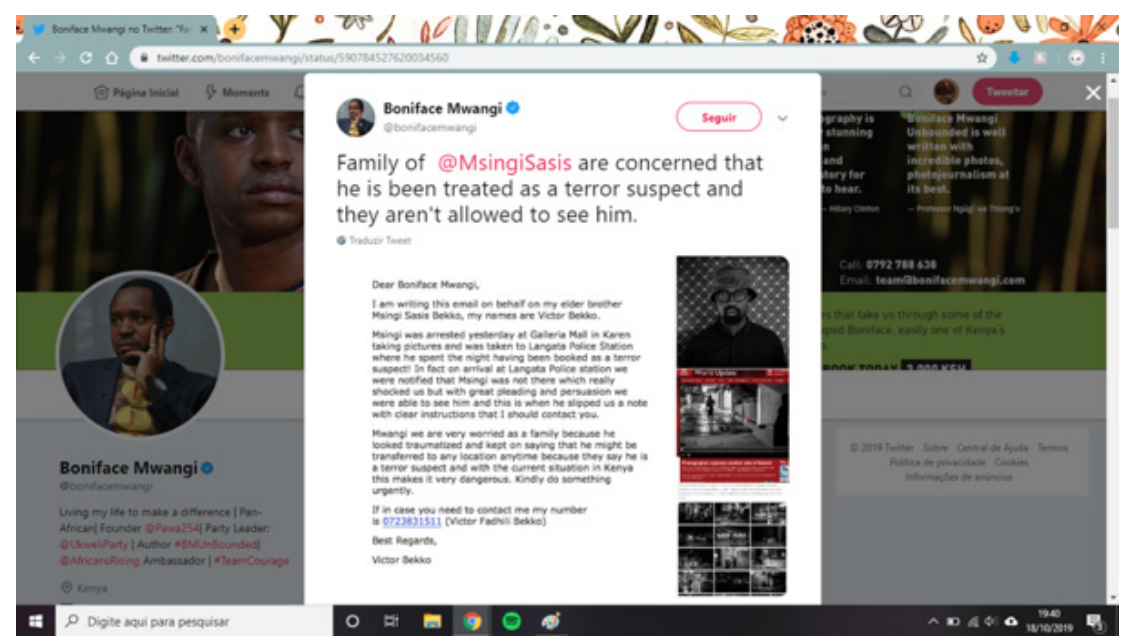

Fonte: Reprodução - Captura de tela.

\section{i) Gerenciamento do Momento Crítico}

Algumas semanas depois de ser despejado, ainda nas ruas, Msingi encontrou, por acaso, uma pessoa que conhecia e ficou sabendo que as pessoas estavam procurando por ele nas mídias sociais. Ele aproveitou essa informação para publicar um pedido de ajuda no Facebook, incentivando seus seguidores a comprarem suas fotografias para que ele pudesse se reestabelecer.

\section{j) Superação do Momento Crítico}

A visibilidade voltou a auxiliar Msingi na reconquista de seu reconhecimento artístico. Ao mesmo tempo, a comunidade de seguidores que ele havia formado ofereceu apoio, mais uma vez, comprando suas fotos para que pudesse recolocar a vida nos eixos e montar um novo estúdio fotográfico. 
Figura 7 - O Modelo Escalas da Visibilidade aplicado ao Nairobi Noir.

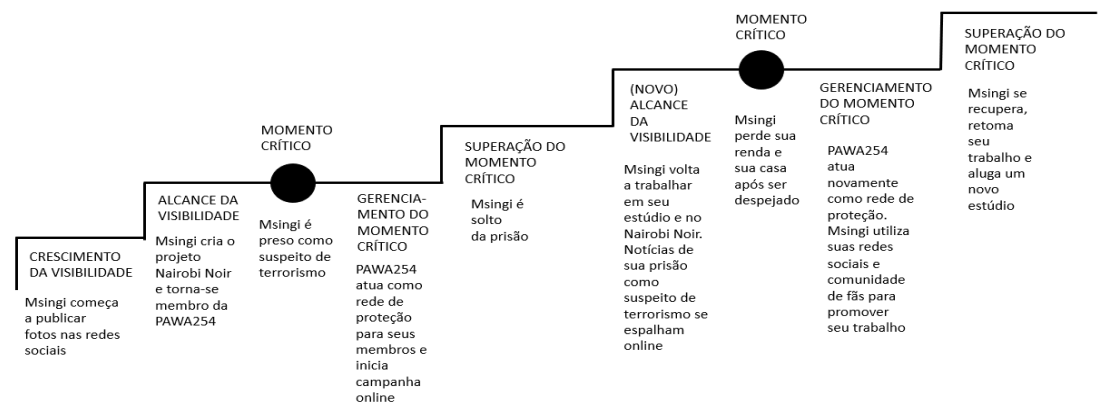

Fonte: autoras.

Nos dois casos, os ativistas adotaram estratégias diferentes para superar seus momentos críticos e administrar a visibilidade não intencional. Um elemento-chave no percurso de visibilidade do Nairóbi Noir foi sua relação com uma forte rede de ativistas e com Boniface Mwangi, um artista famoso e bem conectado no país. Sua organização, a PAWA254, obteve sucesso quando foi necessário fazer pressão para a soltura de Msingi, através de uma utilização estratégica da visibilidade em suas redes sociais. No Rio de Janeiro, as táticas do "Maré Vive" (LOKOT, 2018) incluíram um apelo à grande mídia comercial. Com isso, os ativistas conseguiram neutralizar os efeitos negativos causados pela página falsa que havia colocado a reputação e a vida deles em risco. Como sugeriu De Backer (2018), foi possível ver as maneiras em que elementos de controle e reconhecimento se mesclaram. O reconhecimento alcançado pela página na comunidade se transformou em vigilância e controle - de fato, a página foi atacada porque talvez tenha se tornado demasiadamente reconhecida. Foi necessário então que o amplo alcance da grande mídia comercial tornasse visível a relevância social dessa iniciativa, prevenindo que os ataques causassem mais danos aos ativistas. Ademais, os ativistas puderam perceber que o momento crítico gerado pelo rápido alcance de visibilidade da página significava a adoção de algumas medidas de cautela, como a necessidade de manter anônimas as identidades das pessoas que estavam por trás da página. Essa decisão de 
promover uma rotação dos times de ativistas responsáveis pela página, evitando a associação de suas contas com a administração dos perfis (Entrevista, "Midiativista Maré Vive", 18/06/2019) representa um esforço de contra-vigilância. Como afirma Dencik et al. (2016), esses esforços vão além de soluções tecno-legais, como a utilização de ferramentas de aumento de privacidade já que esses grupos de ativistas não fazem parte de um público especializado em tecnologias.

\section{Considerações Finais}

Com esses dois estudos de caso, encontramos confirmação para perspectivas de autores que destacam as ambiguidades inerentes ao conceito de visibilidade. O trabalho de De Backer é útil na medida em que ele articula as duas faces das consequências do alcance de visibilidade - reconhecimento e controle - e suas imbricações. De fato, elas podem até ocorrer de forma simultânea com o reconhecimento transformando-se em controle e vice-versa (2018, p. 2). Em nosso estudo, percebemos que o midiativismo tem um caráter transgressor, voltado à transformação da realidade (BRAIGHI e CÂMARA, 2018). Nesse contexto, a visibilidade é fundamental para a comunicação de causas ativistas, porém, ao mesmo tempo, traz desafios significativos para os mesmos. Neste artigo, nosso objetivo não era tanto o de identificar os esforços contra-vigilância realizados por ativistas. Ao adotar uma perspectiva do Sul Global, nosso intuito foi destacar os percursos de visibilidade dos ativistas, identificando as conquistas e desafios trazidos pelo alcance de visibilidade ou pela manutenção de invisibilidade.

Midiativistas de comunidades marginalizadas ou aqueles que lidam com a marginalização geralmente têm necessidade de realizar seu trabalho com recursos muito limitados, com pouco tempo para se preparar para o futuro. Este artigo teve como objetivo oferecer uma ferramenta, o Modelo de Escalas da Visibilidade, para que possamos mapear seus percursos de visibilidade até a superação dos ou retração pelos momentos críticos. Argumentamos que esses momentos críticos irão inevitavelmente acontecer com o alcance de visibilidade. Isso ocorre 
como consequência das maneiras em que midiativistas de comunidades marginalizadas são tratados como inimigos da sociedade. Nesses contextos, a desobediência civil adquire significados diversos. Causas legítimas, como a luta contra a violência policial ou a representação artística de questões sociais podem ser reprimidas com punições, prisões e até execuções. Com isso, confirmamos que, ao nos deslocar do eixo do Norte para o Sul Global, o alcance de visibilidade pode trazer uma magnitude maior com consequências igualmente maiores e mais sérias.

No entanto, o modelo apresenta limitações. Aqui, cabe observar que os percursos de visibilidade dos ativistas nem sempre seguem uma trajetória crescente, como poderíamos inferir pelas representações gráficas incluídas neste artigo. Na realidade, eles parecem depender das estratégias utilizadas pelos grupos já que os mesmos podem optar por tornarem-se invisíveis a fim de mitigar uma crise por um período de tempo, interrompendo suas atividades online. A representação gráfica dos percursos de visibilidade do "Maré Vive" e do "Nairobi Noir" foi referente a eventos que transformaram as vidas dos ativistas, já que não foi possível incluir uma variedade mais ampla de eventos. Afinal, o modelo precisava ser simples para que pudesse servir de referência para midiativistas, sem que se fizesse necessário um alto grau de especialização técnica. Além disso, não é nossa intenção tentar prever o futuro de iniciativas ativistas com base em um número pequeno de casos. Após o desenvolvimento do modelo com base em dois casos, como um próximo passo, faz-se necessária a condução de mais pesquisas sobre como o mesmo pode ser aplicado a um número maior de casos em países do Sul Global. 


\section{Referências}

ASKANIUS, Tina; ULDAM, Julie. Online social media for radical politics: climate change activism on youtube. International Journal of Electronic Governance, Athens, v. 4, n. 1/2, p. 69-84, 2011. Disponível em: http://dx.doi.org/10.1504/ijeg.2011.041708. Acesso em: 2 jul. 2020.

BRAIGHI, Antônio Augusto; CÂMARA, Marco Túlio. O que é Midiativismo? Uma proposta conceitual. In: BRAIGHI, Antônio Augusto; LESSA, Cláudio; CÂMARA, Marco Túlio (Org.). Interfaces do Midiativismo: do conceito à prática. Belo Horizonte: CEFET-MG, 2018. p. 25-42.

BRIGHENTI, Andrea. Visibility in Social Theory and Social Research. New York: Palgrave Macmillan, 2010.

BRIGHENTI, Andrea. Visibility: a category for the social sciences. Los Angeles: Current Sociology, v. 55, n. 3, p. 323-342, maio 2007.

CALLUS, Paula. The rise of Kenyan political animation: tactics of subversion. In: LIMB, Peter; OLANIYAN, Tejumola. Taking African Cartoons Seriously: politics, satire, and culture. East Lansing: Michigan State University Press, 2018, p. 71-98.

CUSTÓDIO, Leonardo. Panorama Global da Comunicação Comunitária como Ação Política Periférica. Revista Mídia e Cotidiano, n. 10, p. 138-157, 2016. Disponível em: https://periodicos.uff.br/midiaecotidiano/article/view/9799/0. Acesso em: 28 novembro 2020.

DE BACKER, Mattias. Regimes of Visibility: hanging out in brussels' public spaces. Newbury Park: Space and Culture, v. 22, n. 3, p. 308-320, 2018.

DENCIK, Lina; HINTZ, Arne; CABLE, Jonathan. Towards data justice? The ambiguity of anti-surveillance resistance in political activism. Newbury Park: Big Data \& Society, v. 3, n. 2, p.1-12, 2016. Disponível em: https://doi.org/10.1177/2053951716679678. Acesso em: 18 maio 2020.

FESTA, Regina. Movimentos sociais, comunicação popular e alternativa. In: FESTA, Regina; LINS DA SILVA, Carlos Eduardo Lins da (Org.). Comunicação popular e alternativa no Brasil. São Paulo: Paulinas, 1986. p. 9-30.

FOUCAULT, Michel. Discipline and punish: the birth of the prison. London: Penguin, 1977.

JORDAN, Tim. Activism! Direct action, hacktivism and the future of society. London: Reaktion Books, 2002.

KI-ZERBO, Joseph. Introdução Geral. In: Ki-Zerbo, Jospeh (Ed.) História Geral da África, I: Metodologia e Pré-História da África, 2.ed. rev. Brasília: UNESCO, 2010. Disponível em: https://unesdoc.unesco.org/ark:/48223/pf0000190249?posInSet=1\&queryI d=2456feae-17e4-48d6-84c9-b4a2097a4801. Acesso em: 28 Setembro 2020.

LOKOT, Tetyana. Be Safe or Be Seen?: how russian activists negotiate visibility and security in online resistance practices. Chapel Hill: Surveillance \& Society, v. 16, n. 3, p. 332-346, 2018. Disponível em: https://ojs.library.queensu.ca/index.php/surveillance-and-society/article/view/6967. Acesso em: 17 maio 2020. 
MANN, Steve. "Sousveillance": inverse surveillance in multimedia imaging. In: ANNUAL ACM INTERNATIONAL CONFERENCE ON MULTIMEDIA, 12., 2004, New York. Anais [...]. New York: Association For Computing Machinery, 2014. p. 620-627. Disponível em: https://doi.org/10.1145/1027527.1027673. Acesso em: 29 abril 2020.

MARÉ VIVE. Nossa História. 25 set. 2018. Facebook: @Marevive. Disponível em: https://www.facebook.com/Marevive. Acesso em: 12 abril 2020.

MAZETTI, Henrique. Da mídia alternativa ao midiativismo: observações históricas e conceituais sobre as práticas de contestação midiática. In: BRAIGHI, Antônio Augusto; LESSA, Cláudio; CÂMARA, Marco Túlio (Org.). Interfaces do Midiativismo: do conceito à prática. Belo Horizonte: CEFET-MG, 2018. p. 78-94.

MCCOSKER, Anthony. Social Media Activism at the Margins: managing visibility, voice and vitality affects. Newbury Park: Social Media + Society, v. 1, n. 2, p. 1-11, 2015. Disponível em: http://dx.doi.org/10.1177/2056305115605860. Acesso em: 18 maio 2020.

MEDRADO, Andrea; SOUZA, Renata; CABRAL, Taynara. Ativismo digital de favelas como formas de infraestrutura comunicacional urbana. In: BRAIGHI, Antônio Augusto; LESSA, Cláudio; CÂMARA, Marco Túlio (Org.). Interfaces do Midiativismo: do conceito à prática. Belo Horizonte: CEFET-MG, 2018. p. 278-299.

MERRIAM, Sharan. Qualitative Research and Case Study Applications in Education. 2th. ed. Revised and Expanded San Francisco: Jossey-Bass Publishers, 1998.

MILAN, Stefania; TRERÉ, Emiliano. Big Data from the South(s): beyond data universalism. Oxfordshire: Television Æ New Media, v. 20, n. 4, p. 319-335, 2019. Disponível em: http://dx.doi.org/10.1177/1527476419837739. Acesso em: 2 maio 2020.

MILLER, Frederick D. The end of SDS and the emergence of weatherman: demise through success. In: FREEMAN, Jo; ROWMAN, Victoria Johnson. Waves of Protest: social movements since the sixties. Lanham: Rowman \& Littlefield Publishers, 1999. p. 303-324.

MORAGA, Chérie; ANZALDÚA, Gloria. This bridge called my back: writings by radical women of colour. New York: Kitchen Table, 1983.

NEUMAYER, Christina; SVENSSON, Jakob. Activism and radical politics in the digital age. Oxfordshire: Convergence: The International Journal of Research into New Media Technologies, v. 22, n. 2, p. 131-146, 2014. Disponível em: https://doi. org/10.1177/1354856514553395. Acesso em: 18 maio 2020.

PASQUINELLI, Matteo. Mediactivismo: activismo en los medios - estrategias y prácticas de la comunicación independiente. Roma: Derive Approdi, 2002.

PERUZZO, Cicília Krohling. Cidadania comunicacional e tecnopolítica: feições do midiativismo no âmbito dos movimentos sociais populares. In: BRAIGHI, Antônio Augusto; LESSA, Cláudio; CÂMARA, Marco Túlio (Org.). Interfaces do Midiativismo: do conceito à prática. Belo Horizonte: CEFET-MG, 2018. p. 43-61.

SANTOS, Boaventura de Sousa. Epistemologies of the South: justice against epistemicide. London; New York: Routledge, 2014.

SIMONS, Helen. Case study research in practice. Oxfordshire: Helen Simons, 2009. 
ULDAM, Julie. Social media visibility: challenges to activism. Oxfordshire: Media, Culture \& Society, v. 40, n. 1, p. 41-58, 2017. Disponível em: https://doi. org/10.1177/0163443717704997. Acesso em: 2 maio 2020.

VILLALOBOS, Chloé Beltza. Decolonizing Security and (Re)Imagining Safety in Rio de Janeiro and Nairobi. 2019. 81 f. Dissertação (Mestrado) - Curso de Human Rights And Humanitarian Action, Paris School Of International Affairs, Institut D’Études Politique de Paris, Paris, 2019.

WACHANGA, D. Ndirangu. Kenya's indigenous radio stations and their use of metaphors in the 2007 election violence. Bistrol: Journal Of African Media Studies, v. 3, n. 1, p. 109-125, 2011.

\section{Sobre os autores:}

Andrea Medrado - Professora do Departamento de Comunicação Social e do Programa de Pós-Graduação em Mídia e Cotidiano da Universidade Federal Fluminense. Atuou como Co-Investigadora na Rede eVoices Redressing Marginality, financiada pelo Arts and Humanities Research Council (AHRC) do Reino Unido. Em julho de 2020, foi eleita Vice-Presidente da International Association for Media and Communication Research (IAMCR). Completou pesquisa de Pós-Doutorado pela Royal Holloway University of London, obteve Doutorado pela University of Westminster e Mestrado com bolsa Fulbright pela University of Oregon. Pesquisas temáticas relacionadas ao midiativismo, comunidades marginalizadas e comunicação Sul-a-Sul. No presente artigo, com base em dados obtidos no projeto eVoices Redressing Marginality (financiado pelo Arts and Humanities Research Council - AHRC), desenvolveu o modelo descrito no artigo, além de fazer a redação em língua portuguesa do texto.

Isabella Rega - Professora e pesquisadora na Bournemouth University e na Instituição Jesuit Worldwide Learning: Higher Education at the Margins (JWL). Na Bournemouth University, atua como Professora Associada em Mídias Digitais para a Transformação Social no Departamento de Mídia e Comunicação. É Vice-Coordenadora do CEMP - Centre of Excellence in Media Practice. É Coordenadora do Centro de Pesquisas Media and Digital Literacies e faz parte do Civic Media Hub. Na instituição JWL, atua como Diretora Global de Pesquisas, coordenando projetos que analisam o impacto do ensino superior 
em comunidades marginalizadas em diversos países do mundo, avaliando o papel das tecnologias digitais em experiências educacionais de alta qualidade. No presente artigo, com base em dados obtidos no projeto eVoices Redressing Marginality (financiado pelo Arts and Humanities Research Council - AHRC), desenvolveu o modelo descrito no artigo.

Data de submissão: 30/08/2020

Data de aceite: 04/02/2021 